\title{
Perancangan Aplikasi Helpdesk Menggunakan Pendekatan Knowledge Management System pada Jurusan Sistem Informasi UIN Syarif Hidayatullah Jakarta
}

\author{
Muthia Anggraini ${ }^{1}$, Evy Nurmiati ${ }^{2}$ \\ ${ }^{1}$ Fakultas Sains dan Teknologi, Universitas Islam Negeri Syarif Hidayatullah Jakarta, \\ Jl. Ir H. Juanda No 95, Cemp. Putij, Kec. Ciputat, Kota Tangerang Selatan, Indonesia, 15412 \\ e-mail: ${ }^{1}$ muthia.anggraini17@mhs.uinjkt.ac.id, ${ }^{2}$ evy.nurmiati@uinjkt.ac.id
}

Submitted Date: December $20^{\text {th }}, 2020$

Revised Date: February $05^{\text {th }}, 2021$
Reviewed Date: January $13^{\text {th }}, 2021$

Accepted Date: April 01 ${ }^{\text {st }}, 2021$

\begin{abstract}
Syarif Hidayatullah State Islamic University of Jakartais an educational institution that is tasked with providing quality knowledge and education to students in educating the nation's children. In the current era of globalization, there is knowledge that must be managed for agencies. To achieve this, it is necessary to use existing information technology, namely the online-based Knowledge Management System application. In the world of education, a helpdesk application that helps in improving existing performance and competence. The helpdesk application is widely used by companies and agencies, this application helps facilitate the work of the university technician section. In addition, this helpdesk application makes it easy for students to report damaged campus facilities, so that the technician will make repairs quickly. By looking at this situation, we need a web-based helpdesk application that can coordinate information between technicians and students using the PHP programming languages and My SQL as database design.
\end{abstract}

Keyword: Knowledge, Helpdesk, PHP, My SQL, Database

\section{Abstrak}

Universitas Islam Negeri Syarif Hidayatullah Jakarta merupakan sebuah instansi pendidikan yang bertugas untuk memberikan pengetahuan dan pendidikan yang berkualitas kepada para mahasiswa dalam mencerdaskan anak bangsa. Pada era globalisasi yang berkembang saat ini sebuah knowledge hal yang wajib dikelola bagi intansi. Untuk mewujudkan hal itu, diperlukan pemanfaatan teknologi informasi yang ada yaitu dengan aplikasi Knowledge Management System berbasis online. Pada dunia pendidikan, suatu aplikasi helpdesk yang membantu dalam peningkatan kinerja serta kompentensi yang ada. Aplikasi helpdesk banyak digunakan oleh perusahaan dan instansi, aplikasi ini membantu memudahkan pekerjaan bagian teknisi universitas. Selain itu, aplikasi helpdesk ini memudahkan mahaiswa untuk melaporkan fasilitas kampus yang rusak, sehingga pihak teknisi akan melakukan perbaikan secara cepat. Dengan melihat keadaan tersebut maka dibutuhkan suatu aplikasi helpdesk berbasis web yang dapat mengkoordinasi informasi antara teknisi dan mahasiswa dengan menggunakan bahasa pemograman $P H P$ dan My SQL sebagai perancangan database.

\section{Kata Kunci: Knowledge, Helpdesk, PHP, My SQL, Database}

\section{Pendahuluan}

Pada era saat ini, perkembangan teknologi informasi sudah menjangkau semua elemen dalam kehidupan manusia. Hal ini dapat dilihat dari cara bagamaimana informasi yang dicari dapat diperoleh dengan cepat, tepat, dan juga akurat. Dengan adanya perkembangan teknologi informasi ini dapat memberikan perubahan baru yang memberikan dampak dalam berkehidupan.
Kemajuan teknologi ini membuat instansi, organisasi menggunakan teknologi berbasi digital untuk membantu pekerjaannya karena bersifat lebih efektif dan efisien. Dengan kemajuan teknologi ini akan membantu instansi meningkatkat kinerja intansinya (Darmawan \& Senjaya, 2018). Tuntutan kebutuhan terhadap informasi dan penggunaan internet mendorong terbentuknya suatu aplikasi yang dapat membantu 
dalam menyelesaikan masalah pada mahasiswa, dosen, dan karyawan selama melaksanakan perkuliahan di kampus. Hal ini dapat dilihat pada intansi Universias Islam Negeri Jakarta.

Salah satu yang ikut berperan dalam perkembangan teknologi informasi saat ini adalah Jurusan Sistem Informasi pada Universitas Islam Negeri Jakarta. Universitas Islam Negeri Jakarta merupakan sebuah instansi yang yang bergerak dibidang pendidikan tinggi islam modern yang mempunyai tugas untuk memberikan pengetahuan dan pendidikan yang berkualitas kepada para mahasiswa untuk mencerdaskan anak bangsa. Tentu saja kampus berskala besar ini sudah menggunakan teknologi informasi dan komunikasi berupa komputer dan perangkat pendukung lainnya. Terlebih lagi kampus ini memiliki banyaknya fakultas yang adam mengharuskan adanya penggunaan teknologi informasi untuk meningkatkan kinerja para mahasiswa, dosen, dan juga karyawan. Dengan seringnya penggunaan teknologi informasi berupa komputer dan perangkat pendukung lainnya maka pasti akan mengalami masalah kerusakan teknis dan kendala dalam pengoperasiannya. Khususnya pada jurusan sistem informasi di Universitas Islam Negeri Jakarta ini mempunyai fasilitas penunjang pelajaran yang dapat digunakan oleh mahasiswa dan juga dosen, apabila ada kerusakan barang maka mahasiswa akan melaporkan maasalah tersebut kepada teknisi tersebut secara langsung, namun dengan banyak nya laporan yang masuk sering terjadinya kehilangan data bahkan para teknisi lupa bahwa ada fasilitas yang rusak sehingga akan menggangu kegiatan pembelajaran.

Berdasarkan masalah diatas, maka diperlukan suatu Knoweledge Managament System berupa sebuah aplikasi helpdesk berbasis website yang dibentuk untuk mempermudah pihak teknisi dalam menyelesaikan masalah tanpa harus kehilangan data. Aplikasi helpdesk merupakan aplikasi yang dapat memudahkan para user untuk berkomunikasi dengan pihak teknis kampus untuk menyelesaikan masalah dengan cepat. Aplikasi ini sudah banyak digunakan di dalam perusahaan dan juga instans (Wibowo \& Metandi, 2017). Aplikasi ini juga dapat menyimpan data-data barang yang rusak sesuai yang telah dilaporkan oleh user. Aplikasi ini juga membuat para teknisi mengidentifikasi barang yang rusak secara cepat. Aplikasi helpdesk ini diharapkan dapat memambantu para user dalam memberikan solusi permasalahan yang dihadapi user, mengelola setiap keluhan/permintaan pengguna dan tindak lanjutnya.

Knowledge Management System merupakan sebuah sistem yang diciptakan untuk memfasilitasi penangkapan, penyimpanan, pencarian, transfer dan penggunaan kembali suatu informasi atau dokumentasi. KMS ini berfungsi untuk menyediakan dasar nlai bagi perusahaan, menstimulasi dalam keagiatan manajemen agar fokus pada hal-hal yang penting (Sonatha, Rahmayuni, Alanda, \& Saputra, 2018). Aplikasi ini dapat melakukan input data, edit data, hapus data, mencari data, dan juga menyimpan data yang telah dibuat.

Oleh karena itu, pada penelitian ini peneliti membuat rancang bangun aplikasi helpdesk berbasis website sehingga dapat menjadi suatu apliaksi yang mudah di akses oleh mahasiswa dan juga teknisi kampus. Aplikasi helpdesk ini juga akan memudahkan mahasiswa dalam melaporkan kerusakan fasilitas kampus agar dapat di identifikasi oleh pihak teknis secara cepat. Teknisi juga akan mengetahui semua fasilitas yang mengalami kerusakan dan dapat melihat rekam jejak kerusakan fasilitas tersebut. Sehingga permasalahan ini tidak menjadi alasan untuk mengganggu kegiatan pembelajaran.

\section{Tinjauan Pustaka}

Berdasarkan hasil penelitian sebelumnya (Irawan \& Setiyorini, 2017), penelitian ini membahas tentang Kendala dan kesulitan sering dialami oleh teknisi PT. Indah Kiat dalam mengelola laporan kerusakan serta dalam memberikan penanganannya untuk itu perlu adanya sistem untuk mengelola laporan serta membantu dalam memberikan solusi yang tepat dalam menanganinnya. Maka dibuatlah rancang bangun aplikasi helpdesk Dengan penambahan fitur knowledge management untuk menyelesaikan permasalah an kerusakan dengan mencari dalam basis pengetahuan yang direkam untuk menentukan solusi apa yang tepat, berdasarkan pengetahuan yang dimiliki oleh tiap-tiap teknisi untuk dibagikan kepada teknisi lain yang memiliki permasalahan yang sama dalam menyelesaikan kerusakan. metode yang digunakan dalam membangun aplikasi helpdesk dengan menggunakan pendekatan knowledge management system adalah Waterfall model dan dirancang dengan diagram UML (Unified Modeling Language). Bahasa pemrogramman yang digunakan adalah PHP dengan database MySQL. Dengan dibangunya aplikasi helpdesk dengan 
menggunakan pendekatan knowledge management system diharapkan dapat menjadi alat untuk membantu pengelolaan laporan kerusakan dan pengetahuan tentang kerusakan serta solusi yang tepat untuk menyelesaikan kerusakan berdasarkan basis pengetahuan yang sudah ada.

Pada penelitian selanjutnya (Saefudin, 2011), membahas tentangrancang bangun aplikasi ticketing helpdesk kantor. Hal ini dikarenakan kantor masih menggunakan helpdesk sistem lama dengan menerima dan mencatat keluhan yang dilaporkan melalui media telepon atau bertatap muka secara langsung dengan user yang memiliki keluhan. Aplikasi ini dihadapkan pada permasalahan lambatnya kinerja helpdesk dalam mencatat dan mendapatkan informasi keluhan sehingga berakibat tidak efektifnya penanganan atas keluhan yang terjadi. Aplikasi ticketing sengaja dibuat untuk menggantikan fungsi dari helpdesk. Aplikasi ini diharapakan Ketika terjadi kendala, user yang sudah terdaftar sebagai pengguna dapat melakukan login kedalam aplikasi ticketing untuk membuat laporan keluhan secara langsung ke pihak engineer, sehingga problem dapat langsung ditangani

Mengacu pada penelitian berikutnya (Sonatha, Rahmayuni, Alanda, \& Saputra, 2018), membahas tentang rancang bangun aplikasi knowledge management berbasis web, Untuk mengelola dan mendokumentasikan pengetahuan sehingga menjadi referensi bagi karyawan dalam perusahaan diperlukan penyusunan dan penerapan sistem manajemen pengetahuan yang tepat. Penerapan sistem manajemen pengetahuan, tentunya harus didukung oleh fitur-fitur yang dibutuhkan untuk menyimpan dan mengorganisasikan pengetahuan yang ada. Untuk mengatasi masalah ini, dirancang sistem manajemen pengetahuan yang dibuat dalam bentuk sistem pemograman berbasis web menggunakan bahasa pemograman PHP dengan Framework GTFW dan MySQL. Sistem manajemen pengetahuan memiliki fasilitas pencarian data dokumentasi, penyimpanan catatan masalah dan informasi berita serta fitur download data dari setiap dokumentasi yang ada.

Penelitian lainnya (Bahrudin, Ridwan, \& Darmojo, 2019), membahas tentang penerapan helpdesk ticketing system dalam penangan keluhan penggunaan sistem informasi berbasi web pada Unit Pelaksana Tugas Information Technology (UPT IT) yang merupakan pusat penyedia informasi Akademik yang ada pada kampus Universitas Islam Syekh-Yusuf. ketika terjadi keluhan tentang gangguan Sistem Informasi Akademik (SINA) seperti nilai tidak sesuai, masalah registrasi atau masalah keuangan, user masih harus datang langsung ke kantor teknisi IT untuk melaporkan keluhannya, user juga bingung harus melapor kesiapa ketika teknisi IT tidak berada ditempat laporanlaporan yang masuk tidak terdokumentasi dengan baik. Untuk mengatasi masalah diatas dibutuhkan suatu aplikasi helpdesk ticketing untuk menjadi wadah user melaporkan masalah. Pendekatan pemgemabangan sistem ini menggunakan metode prototype, aplikasi ini dirancang memanfaatkan web application sebagai platformnya dengan MySQL sebagai databasenya. Hasil dari penelitian ini adalah terancangnya aplikasi helpdesk ticketing untuk mempermudah user dalam melakukan pelaporan masalah, dan memudahkan Teknisi IT dalam mengelola laporan.

\section{Metodologi Penelitian}

Penelitian ini menggunakan metode waterfall yang dapat dilihat pada Gambar 1 di bawah ini.

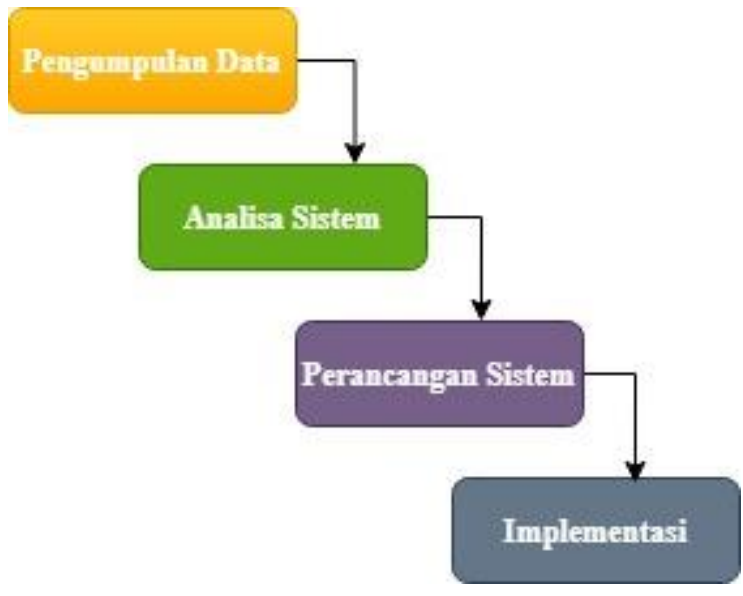

Gambar 1 Metode Waterfall

Tahapan pengembangan sistem menggunakan metode waterfall dijelaskan pada subbab berikutnya.

\subsection{Pengumpulan Data}

Pengumpulan data dilakukan dengan beberapa cara, yaitu:

1) Metode Observasi

Penelitian dilakukan dengan pengamatan langsung ke lokasi yang menjadi objek penelitian yaitu kebagian teknisi fakultas sains dan teknologi sehingga mendapatkan data yang dibutuhkan dalam penelitian ini. Hal yang 
diamati adalah seluruh aktifitas yang berkaitan dengan penelitian ini.

2) Metode Studi Pustaka

Penelitian ini menggunakan beberapa referensi yang relevan sebagai acuan berupa buku-buku, jurnal penelitian serta artikel lainnya yang berh ubungan dengan penelitian yang akan dikembangkan dan dengan cara mencari teori-teori untuk dijadikan sebagai landasan teori yang akan sangat membantu dalam mendapatkan informasi yang dibutuhkan.

\subsection{Analisa Sistem}

Analisa mencakup analisa pengguna dan kebutuhan, yaitu:

1) Analisa Pengguna

Pengguna merupakan seseorang yang membutuhkan aplikasi helpdesk untuk membantu dalam menyelesaikan permasalahan yang dihadapi. Admin merupakan pengguna sistem yang mempunyai hak akses dalam menginput, mengedit, dan menghapus data-data yang terdapat di dalam aplikasi helpdesk. Pihak tekniksi merupakan karyawan universitas yang mempunyai hak askses dalam menerima informasi keluhan masalah kerusakan fasilitas kampus dan juga dapat memberikan informasi antara teknis universitas melalui chat forum. Mahasiswa merupakan pengguna sistem yang melaporkan permasalahan kerusakan fasilitas

2) Analisa Kebutuhan

Analisa kebutuhan sistem merupakan proses mengumpulkan, menganalisis kebutuhan dari sistem. Pada analisa aplikasi helpdesk yang telah ada sebelumnya pada Universitas Islam Negeri Jakarta dibutuhkan ketelitian dalam pengolahan data. Dilihat dari waktu penyelesaian masalah yang dilaporkan tidak efisien karena masih menggunakan sistem manual tanpa ada aplikasi yang membantu penyelesaian dan pendataan permasalahan. Penelitian ini mengusukan kepada pihak Universitas Islam Negeri Jakarta untuk menggunakan aplikasi yang dapat meningkatkan produktivitas sehingga dapat menyelesaikan permasalahan dengan cepat dan akurat. Pendataan permasalahan merupakan sebuah kebutuhan akan adanya konsistensi yang sesuai dengan tujuan sistem. Dari permasalahan diatas maka diperlukan rancang bangun aplikasi helpdesk berbasis web yang dapat memecahkan permasalahan.

\subsection{Perancangan Sistem}

Pada tahap perancangan aplikasi helpdesk ini dibutuhkan salah satu diagram yang digunakan yaitu perancangan Use Case, yang akan ditampilkan pada gambar dibawah sebagai berikut

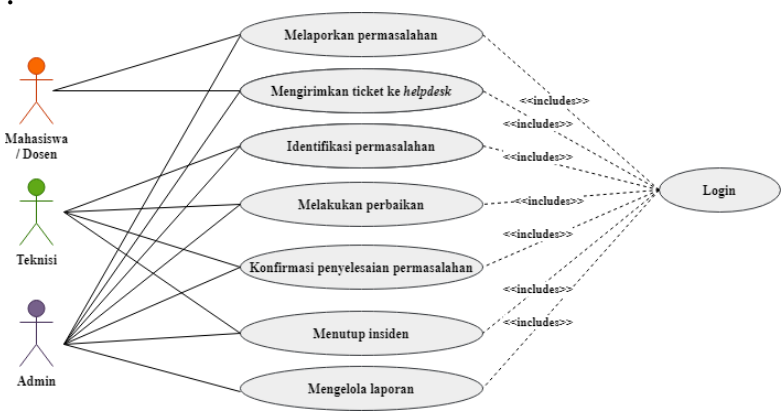

\section{Hasil dan Pembahasan}

Penelitian ini merupakan perancangan aplikasi helpdesk dengan pendekatan knowledge management sytem pada jurusan sistem informasi Universitas Islam Negeri Jakarta yang dibuat untuk memudahkan mahaiswa untuk melaporkan fasilitas kampus yang rusak menggunakan metode waterfall dan juga merekam pengetahuan sebagai solusi untuk pihak tekniksi kampus. Berikut merupakan tampilan menu-menu yang merupakan implementasi sistem yang telah dirancang sebagai berikut:

\section{1) Halaman Login}

Halaman Login, merupakan halaman awal yang muncul ketika pertama kali pengguna mengakses aplikasi.

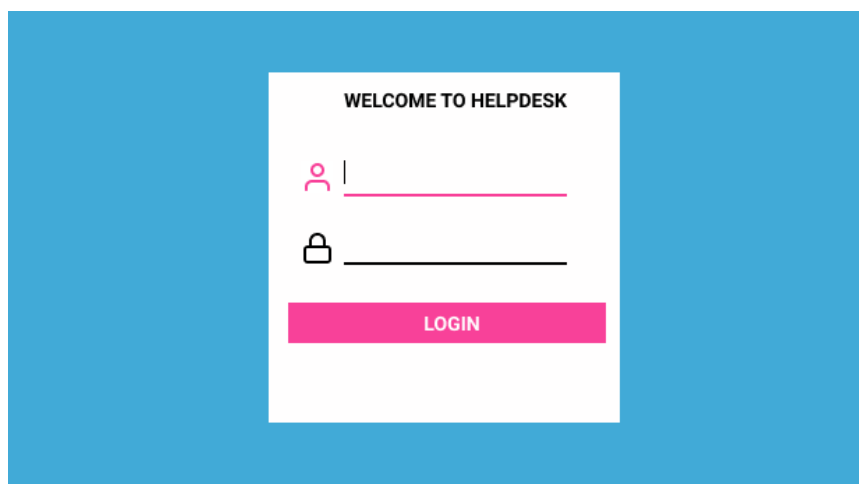

Gambar 2 Halaman Login 
2) Dashboard

Dashboard, merupakan halaman yang muncul setelah pengguna melakukan login dan semua menu yang tersedia dapat digunakan oleh pengguna.

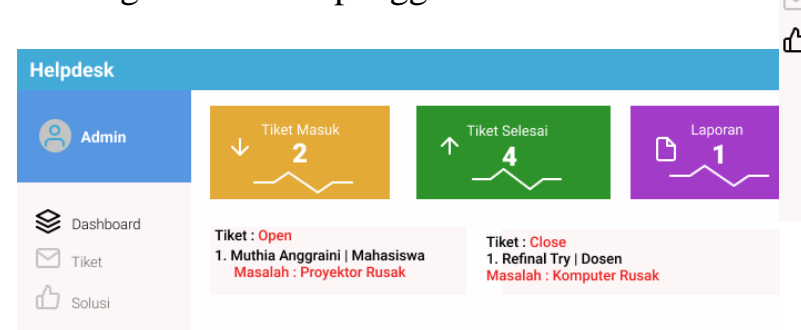

Gambar 3 Dashboard

3) Data Tiket

Data tiket, merupakan salah satu menu yang dapat digunakan pengguna untuk mengirim tiket permintaan penyelesaian masalah kerusakan kepada teknisi, kemudia teknisi akan segera menyelesaikan masalah yang dilaporkan pengguna.

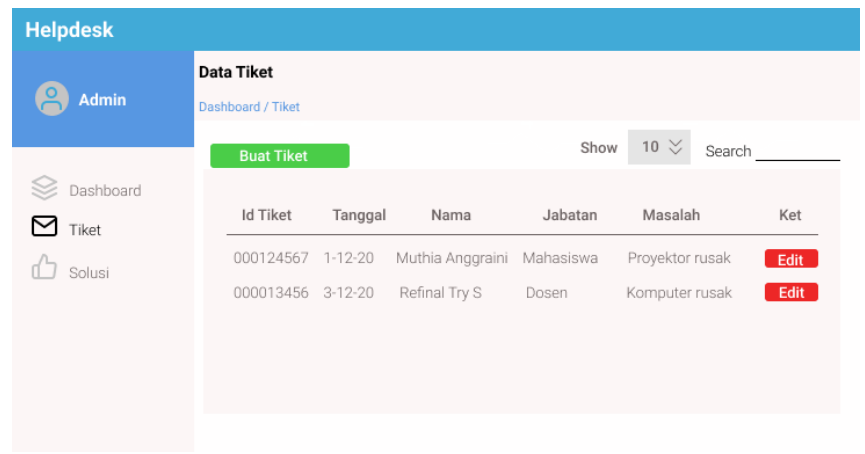

Gambar 4 Data Tiket

4) 4.1.4 Halaman Solusi

Halaman Solusi, merupakan halaman solusi dari permasalahan yang dilaporkan pengguna, pada halaman ini teknisi dapat input pengguna dan juga pengguna dapat melihat proses penyelesaian masalah.

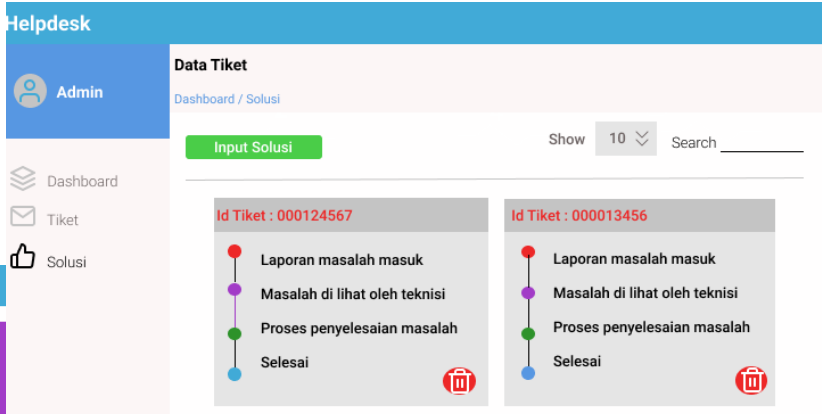

Gambar 5 Halaman Solusi

\section{$5 \quad$ Kesimpulan}

Berdasarkan penelitian rancang bangun aplikasi helpdesk berbasis web yang telah dilakukan, maka dapat diambil kesimpulan sebagai berikut:

1) Aplikasi helpdesk membantu mahasiswa dan juga dosen dalam melaporkan permasalahan fasilitas di jurusan sistem informasi universitas islam negeri Jakarta, pengguna tidak perlu bertemu langsung kepada teknisi untuk melaporkan masalah.

2) Proses penanganan keluhan mahasiswa dan dosen kepada pihak universitas menjadi lebih efisien, cepat, dan mudah dikarenakan disistem sebelumnya masih menggunakan pencatatan buku sehingga akan sulit diipantau apabila banyak keluhan yang masuk.

3) Aplikasi helpdesk memudahkan teknisi dalam menyelesaikan permasalahan yang dilaporkan dan juga memiliki rekam jejak solusi keluhan.

4) Admin dapat melihat laporan permasalahan, sehingga dengan laporan tersebut akan menjadi bahan perbaikan untuk pihak kampus kedepannya.

\section{Saran}

Adapun saran yang dapat peneliti sampaikan pada pengembangan aplikasi helpdesk berbasis web pada jurusan sistem informasi universitas islam negeri Jakarta sebagai berikut:

1) Dengan berkembangnya zaman, penelitian terhadap aplikasi helpdesk ini sebaiknya dapat dikembangkan kedepannya sehingga aplikasi ini dapat menjadi lebih baik dan bermanfaat bagi para pengguna dan juga pihak universitas.

2) Diharapkan dengan adanya aplikasi ini akan meningkatkan produktivitas pembelajaran di kampus, dan disarankan pada pihak universitas agar melakuan 
pemeliharaan dan maintenance terhadap sistem ini.

\section{Referensi}

Bahrudin, R. M., Ridwan, M., \& Darmojo, H. S. (2019). Penerapan Helpdesk Ticketing System Dalam Penanganan Keluhan Penggunaan Sistem Informasi Berbasis Web. Jurnal Teknik Informatika UNIS, 7(1), 71-82.

Darmawan, D., \& Senjaya, W. (2018). Sistem Aplikasi Helpdesk Online Berbasis Web pada PT XYZ. Jurnal Teknik dan Ilmu Komputer, 7(25), 7996.

Irawan, A., \& Setiyorini, N. K. (2017). Rancang Bangun Aplikasi helpdesk Dengan Menggunakan Pendekatan Knowledge Management System Pada Seksi Teknisi pt. Indah kiat pulp \& paper tbk. Protekinfo (Pengembangan Riset dan Observasi Teknik Informatika), 4, 6-11. doi:10.30656/protekinfo.v4i0

Saefudin, M. (2011). Aplikasi Ticketing Helpdesk Kantor dengan PHP dan MySQL. Jurnal Ilmiah "Komputasi" STMIK Jakarta STI\&K, 10, 1-10.

Sonatha, Y., Rahmayuni, I., Alanda, A., \& Saputra, I. (2018). Rancang Bangun Aplikasi Knowledge Management Berbasis Web. INVOTEK: Jurnal Inovasi, Vokasional, dan Teknologi, 8(2), 133140. doi:10.24036/invotek.v18i2.423

Wibowo, N. I., \& Metandi, F. (2017). Rancang Bangun Aplikasi Helpdesk Berbasis Web pada Jurusan Teknologi Informasi Politeknik Negeri Samarinda. Jurnal Sains Terapan Teknologi Informasi, 9(2), 125-132. 